Article

\title{
Spring Moisture Availability is the Major Limitation for Pine Forest Productivity in Southwest China
}

\author{
Yingfeng Bi ${ }^{1,2,3}$, Cory Whitney ${ }^{4} \mathbb{D}$, Jianwen $\mathrm{Li}^{1,2,3}$, Jingchao Yang ${ }^{5}$ and Xuefei Yang ${ }^{1,2,3, *}$ \\ 1 Key Laboratory for Plant Diversity and Biogeography of East Asia, Chinese Academy of Sciences, \\ Kunming 650201, China; biyingfeng@mail.kib.ac.cn (Y.B.); lijianwen@mail.kib.ac.cn (J.L.) \\ 2 Key Laboratory of Economic Plants and Biotechnology, Kunming Institute of Botany, \\ Chinese Academy of Sciences, Kunming 650201, China \\ 3 Southeast Asia Biodiversity Research Institute, Chinese Academy of Sciences, Menglun, \\ Mengla 666303, China \\ 4 Institute of Crop Science and Resource Conservation (INRES)—Horticultural Sciences/Center for \\ Development Research (ZEF), University of Bonn, 53121 Bonn, Germany; cory.whitney@uni-bonn.de \\ 5 Kunming Institute of Survey and Design, State Forestry and Grassland Administration, Kunming 650216, \\ Yunnan, China; yjc1126xny@163.com \\ * Correspondence: xuefei@mail.kib.ac.cn
}

Received: 24 February 2020; Accepted: 9 April 2020; Published: 15 April 2020

check for updates

\begin{abstract}
Forests in low-latitude $\left(0^{\circ} \mathrm{N}-30^{\circ} \mathrm{N}\right)$ regions are important for greenhouse gas sequestration. They harbor around $25 \%$ of vegetation carbon stocks. The productivity of these forests is expected to change as the global climate changes. They may absorb less greenhouse gasses, with negative effects on the global climate. However, little is known about how exactly these forests will respond to climate change. Here, we focus on the largest pine forests in low-latitude forests areas in southwest China. These forests have experienced rapid climate warming over the past 60 years. We collected tree-ring cores from two naturally occurring key afforestation pine tree species: Pinus yunnanensis Franch. and Pinus armandii Franch. in Baoshan and Lijiang of Yunnan. We used basal area increment (BAI) to examine the productivity trends of these two species over long-time scales, and Partial Least Squares regression analysis together with Pearson correlation analysis to identify the critical climate periods for the growth of these two species. We found that: (1) regional pine tree productivity began to decline at the beginning of this century. (2) The radial growth of both species had the strongest positive correlation with the spring Palmer Drought Severity Index (PDSI) and precipitation and the strongest negative correlation with spring temperatures. (3) Climate responses differ by species with higher positive correlations between tree-ring width, PDSI, and precipitation in P. armandii than in P. yunnanensis at similar locations. (4) Climate responses differ by location with higher positive correlations between tree-ring width and PDSI in Lijiang than in Baoshan for P. yunnanensis. Our results suggest that spring moisture availability is the main limiting factor for pine tree growth, especially for P. yunnanensis in Lijiang and P. armandii in Baoshan. Future regional warming and warm-induced drought conditions may have negative effects on the growth of pine trees. These results provide reference data for the sustainable management of pine forests in low-latitude regions of southwest China and may be useful in assessing the sustainable carbon sink ability of pine forests in this region under climate change.
\end{abstract}

Keywords: tree-ring; pine tree; southwest China; climate change

\section{Introduction}

Future climate change is likely to influence the productivity of the world's forests [1]. Changes in forests productivity are expected to effect the climate system at multiple spatiotemporal scales [2], 
as forests play an important role in the global carbon cycle by absorbing atmospheric $\mathrm{CO}_{2}$ and storing it as carbon sinks [3]. Thus, the fate of forests is of major ecological, societal, and economic concern under climate change [4]. Past studies have demonstrated that climate warming can increase tree growth and recruitment in cold biomes [5], but can also lead to growth decline, canopy dieback, and mortality in semi-arid areas [6]. Much of the relevant research effort has been focused on middle-high latitude regions $\left(30^{\circ} \mathrm{N}\right.$ to $\left.60^{\circ} \mathrm{N}\right)$ [7]. Forests in low-latitude regions $\left(0^{\circ} \mathrm{N}\right.$ to $\left.30^{\circ} \mathrm{N}\right)$ should also be studied, since they account for only about $10 \%$ of total global forested area but contain about $25 \%$ of the vegetation carbon stocks [1]. Considering the critical role played by low-latitude forests in the global carbon cycle, it is necessary that we gain a better understanding of their growth trends and how these respond to climate change [1].

The response of forest growth to climate change can only be evaluated when species-specific responses are well understood. Previous research has revealed that growth-climate relationships vary among species and sites, especially in mountainous areas [8-11]. Forests are composed of many species, and they may show variation in response to climate change due to their varied physiological adaptation traits in leaf features, tree size, and wood density, and different growth strategies such as drought or cold tolerance [2]. In addition, forest habitats are diverse in mountainous areas, mainly due to the complex topography, resulting in diverse growth-climate response patterns. Therefore, precise predictions of how mountainous forests respond to climate change require thorough understanding of the relationships between climate factors and the growth of multiple species at multiple representative sites.

Southwest China includes the Tibet Autonomous Region, Sichuan and Yunnan provinces, where most areas belong to low-latitude mountain regions. The region's forests accounted for about $26 \%$ of the national land area in 2010 and stored nearly $40 \%$ of the national carbon [12]. This area is called the "Southwest China Forest Region" and is the second-largest forested area in China [4,9]. These forests contribute greatly to the national and even to the global carbon cycle [3]. This region is currently experiencing a significant warming trend with a temperature increase rate of $0.30{ }^{\circ} \mathrm{C} /$ decade [13], which exceeds the global (approximately $0.14{ }^{\circ} \mathrm{C} /$ decade) [14] and national (approximately $0.15^{\circ} \mathrm{C} /$ decade) [15] warming rates. Forest die-off episodes are frequently reported in this region [16-18]. Sound forest management plans that ensure the long-term carbon sink ability of these forests are urgently needed. Developing these plans will require a thorough knowledge of forest productivity trends and related causes.

Tree-ring widths, which record annual growth rates, are highly sensitive to climate change, they can serve as an effective proxy to evaluate tree growth-climate relationships [2]. Although southwest China was one of the earliest regions for dendroecology research in China [19], past research efforts mainly focused on fir and spruce species [20]. The radial growth of fir and spruce is mainly limited by summer temperatures [21]; it is also partially controlled by winter temperatures [22], and the spring water regime [9]. As of yet, little research has been done on pine forests, although they account for $3 \%$ of the national forest area [23]. It has been speculated that the growth-climate relationship of pine forests may determine their long-term productivity $[18,24]$, which in turn affects the regional climate system.

Pinus yunnanensis Franch. and Pinus armandii Franch. are the dominant pine tree species of the pine forests in the study area. Geographically, P. yunnanensis is naturally distributed across Yunnan, while $P$. armandii is distributed from northern to southern China with a southwestern distribution edge in Yunnan [25]. These species have traditionally served as the key afforestation tree species in the region [3]. Since the 1980s, large-scale reforestation including P. yunnanensis and P. armandii has absorbed as much as $28 \%$ to $37 \%$ of China's $\mathrm{CO}_{2}$ emissions [3]. Yunnan has the region's largest forests, $52 \%$ of which, about five million $\mathrm{hm}^{2}$, are pine forests. These species make up about $32 \%$ of the total timber volume, which is estimated to be around 300 million $\mathrm{m}^{3}$ [16].

Climate warming is expected to impact pine forest growth and timber production in Yunnan, yet little effort has been made to understand their expected responses to climate warming on a long-term 
scale. We attempt to shed light on these issues with an assessment of tree-rings as a window into long-term productivity trends and for identifying limiting factors for radial growth. We collected tree-ring samples from P. yunnanensis and P. armandii from Baoshan and Lijiang, Yunnan to answer two related research questions: (1) What are the long-term productivity trends of $P$. yunnanensis and P. armandii? (2) What are the main limiting factors for their radial growth, and is this consistent across species and sites? Events related to changing climate, such as high-frequency droughts, are speculated to be the cause of episodes of die-offs of pine forests in recent years [16-18]. We hypothesize that the productivity of pine tree species has begun to decline in recent decades due to intensifying aridity periods in dry seasons (previous November to current May) [26]. We further hypothesize that the spring water regime is the main limiting factor for pine tree growth.

\section{Materials and Methods}

\subsection{Study Area}

This study took place in the forests surrounding Haitangwa village of Baoshan and the Lijiang Alpine Botanical Garden, both in Yunnan Province (Figure 1). In the Haitangwa village of Baoshan, pine forests cover around $150 \mathrm{~km}^{2}$ in a hilly region from 500 to 2500 meters above sea level (m a.s.l), and around $20 \%$ of the forests are mixed pine and around $80 \%$ are pure stands of pine (personal contact with local villagers). In the past, the forest were mainly dominated by evergreen broad-leaved trees, but they were logged for timber, cut for fuel wood, and cleared for agricultural land expansion [27]. Now, a large portion of the forests is dominated by pine, mainly P. yunnanensis and P. armandii. These pine forests regenerated naturally after the original evergreen broad-leaved forests were clear-cut, the farmland was abandoned, or the coniferous and broad-leaved mixed forest was disturbed. The forest is protected from logging and used primarily for the harvest of non-timber forest products [27]. In Lijiang Alpine Botanical Garden, pine forests cover a large area from 2600 to $3400 \mathrm{~m}$ a.s.l; P. yunnanensis is the dominant species in this region.

Climatically, the study sites are mainly dominated by the Southwest Summer Monsoon [28], resulting in a contrasting dry season (November-May, Figure 2a,c) and wet season (June-October, Figure 2a,c). The southwest monsoon typically occurs in Baoshan between May 26th and May 31st and in Lijiang between June 6th and June 10th [29]. According to Longya and Lijiang Meteorological Station records from 1951 to 2019 [30], the annual mean temperatures were around $16.2^{\circ} \mathrm{C}$ and $12.8^{\circ} \mathrm{C}$ respectively, with the lowest value in January $\left(9.1^{\circ} \mathrm{C}\right.$ and $\left.6.1{ }^{\circ} \mathrm{C}\right)$ and the highest in June $\left(21.5^{\circ} \mathrm{C}\right.$ and $18.2^{\circ} \mathrm{C}$ ). The total annual precipitation was $970 \mathrm{~mm}$ and $950 \mathrm{~mm}$ in Longya and Lijiang respectively, of which $83 \%$ and $80 \%$ occurs between late May and October. Low-level cloud cover generally increases with the onset of the summer monsoon in late May together with increasing precipitation and relative humidity and decreasing sunshine hours (Figure 2b,d).

Significant warming trends have been observed during the dry and wet seasons; these warming were stronger in the spring season (increasing $0.02-0.30{ }^{\circ} \mathrm{C} /$ decade, Figures S1 and S2). The annual and seasonal total precipitation has not shown any obvious trends (Figures S1 and S2). The annual mean relative humidity has decreased since around 1975 (decreasing $0.23 \%$ /decade), especially for the spring season (decreasing $0.24 \%$ /decade, Figures S3 and S4). This suggests that the climate in our study may be getting drier, especially during spring. 


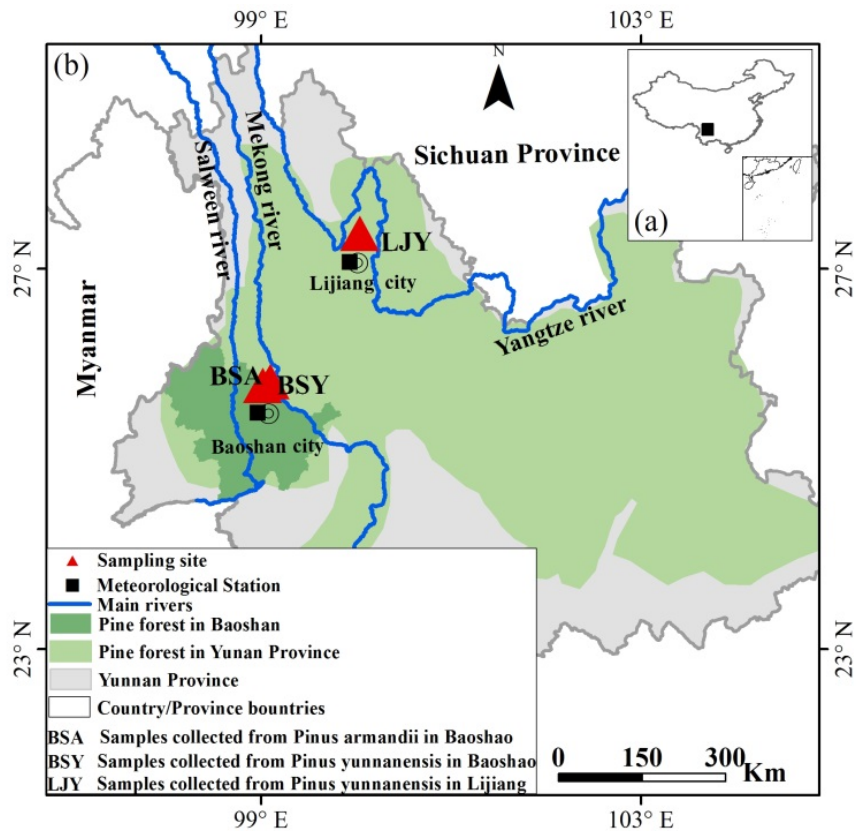

Figure 1. Geographic location of study area in southwest China (a) and locations of tree-ring sampling sites and meteorological stations in Baoshan and Lijiang (b). Note: the distribution area of pine forests is redrawn from the pine distribution map of [31]. BSY $=$ (Baoshan yunnanensis) site where Pinus yunnanensis samples were collected in Baoshan. BYA = (Baoshan armandii) site where Pinus armandii samples were collected in Baoshan. LJY = (Lijang yunnanensis) site where P. yunnanensis samples were collected in Lijiang.
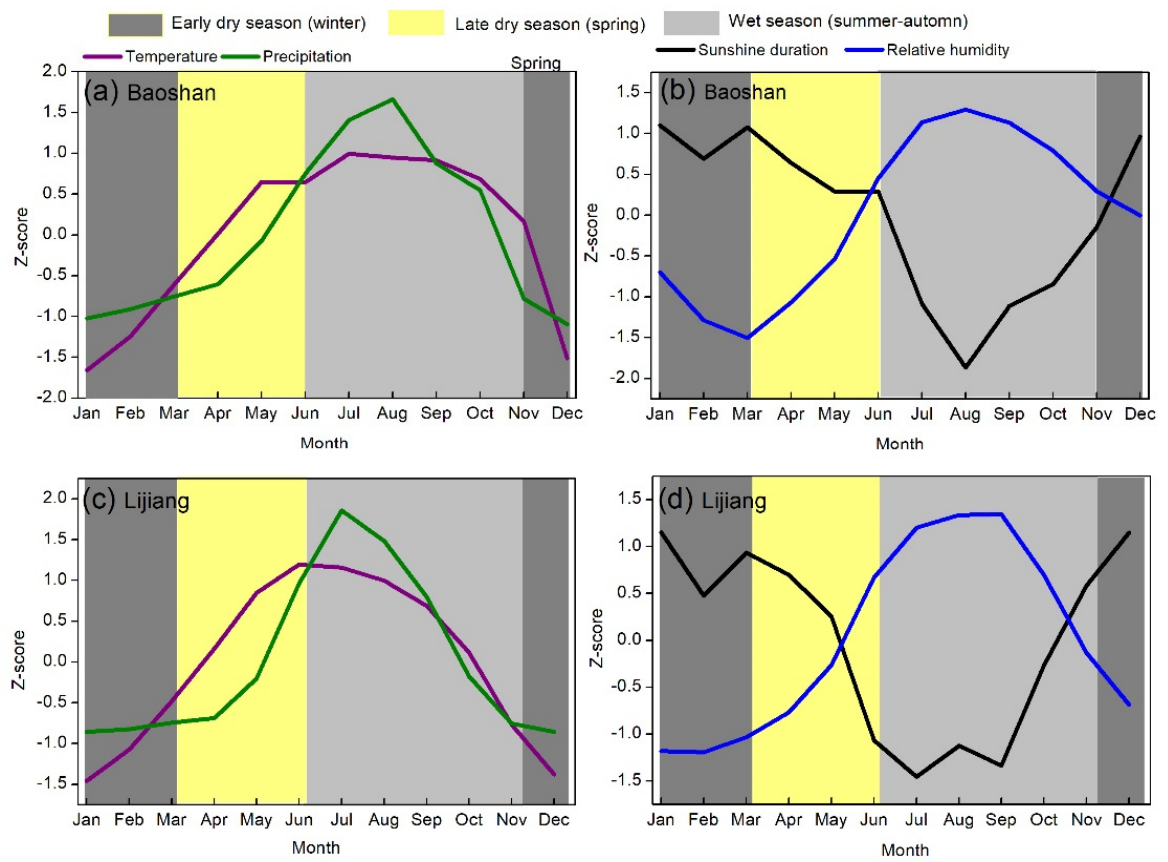

Figure 2. Variations of monthly mean air temperature and precipitation (a and c), and relative humidity and sunshine duration (b and $\mathbf{d}$ ) recorded at Longya and Lijiang Meteorological Stations between 1951 and 2019 in Yunnan, southwest China. All the data were standardized using Z-scores.

\subsection{Sampling and Chronology Development}

According to the law of limiting factors and the basic principle of site selection in dendroclimatological research [32], as well as the objectives of this study, we firstly chose the 
sparse forest as the target forest, and then we selected the edge of the target pine forest as our sampling site. We selected three sampling sites to collect tree-ring cores. Two sites were located in Baoshan: one where P. yunnanensis samples were collected and one where P. armandii samples were collected. We named these sites BSY (Baoshan yunnanensis) and BYA (Baoshan armandii). We also had one site in Lijiang where P. yunnanensis samples were collected. We named this site LJY (Lijang yunnanensis) (Figure 1). BSY and BSA were geographically close together, and LJY was around $250 \mathrm{~km}$ northeast of BSY and BSA. At BSY, P. yunnanensis was the dominant tree species. Commonly associated shrub tree species included Quercus senescens Hand.-Mazz., Dichotomanthes tristaniicarpa Kurz, and Lyonia ovalifolia (Wall.) Drude. At the BSA site, P. armandii was the dominant trees species. Associated shrub tree species included Pieris formosa (Wall.) D. Don, Craibiodendron stellatum (Pierre) W. W. Sm., Myrica nanta Cheval., and Myrsine africana L. At the LJY site, P. yunnanensis was the dominant tree species. Associated shrub tree species included Quercus pannosa Hand.-Mazz. and Rhododendron decorum Franch. During sampling, we collected tree-ring cores from healthy pine trees with no visible insect infection, human or fire disturbance, and with unobstructed canopies with sufficient spatial distance between the canopy of each tree. We took one to three cores per tree from opposite directions at breast height $(1.3 \mathrm{~m})$ with increment borers (Haglof, Dalarna, Sweden). In total, 201 increment cores from 100 trees were sampled (Table 1).

Table 1. Sampling locations and statistics of tree-ring chronologies of pine trees in Baoshan and Lijiang, Yunnan, southwest China.

\begin{tabular}{cccc}
\hline & BSY & BSA & LJY \\
\hline Species & Pinus yunnanensis & Pinus armandii & P. yunnanensis \\
Location & Baoshan & Baoshan & LJY \\
Site code & BSY & BSA & N \\
Elevation (m a.s.l.) & $25.22^{\circ} \mathrm{N} / 99.30^{\circ} \mathrm{E}$ & $25.21^{\circ} \mathrm{N} / 99.30^{\circ} \mathrm{E}$ & $27.00^{\circ} \mathrm{N} / 100.19^{\circ} \mathrm{E}$ \\
Latitude/longitude (degree) & 2350 & 2351 & 3229 \\
Name meteorological Station & Longya Station & Longya Station & Lijiang Station \\
PDSI grid & $25.25^{\circ} \mathrm{N} / 99.25^{\circ} \mathrm{E}$ & $25.25^{\circ} \mathrm{N} / 99.25^{\circ} \mathrm{E}$ & $26.75^{\circ} \mathrm{N} / 100.25^{\circ} \mathrm{E}$ \\
Trees (cores) & $33(66)$ & $52(103)$ & $24(41)$ \\
Time span (year) & $1983-2016$ & $1979-2016$ & $1967-2017$ \\
Average radial growth rate (mm) & 3.64 & 2.62 & 2.36 \\
Mean sensitivity (MS) & 0.35 & 0.26 & 0.30 \\
Mean inter-series correlation (Rbar) & 0.21 & 0.26 & 0.28 \\
First-order autocorrelation (AC1) & 0.49 & 0.72 & 0.34 \\
Expressed population signal (EPS) & 0.32 & 0.34 & 0.40 \\
EPS $>$ 0.85 & 0.97 & 0.99 & 0.93 \\
Mean segment length (MSL) & 1988 & 1984 & 1970 \\
\hline
\end{tabular}

BSY = (Baoshan yunnanensis) site where Pinus yunnanensis samples were collected in Baoshan. BYA = (Baoshan armandii) site where Pinus armandii samples were collected in Baoshan. LJY = (Lijang yunnanensis) site where P. yunnanensis samples were collected in Lijiang, PDSI = Palmer Drought Severity Index.

We followed the sample preparation and measurement principles (Stokes and Smiley, 1968). First, we first smoothed the wood surface of each of the increment cores to increase the visibility of individual tree-ring boundaries by using progressively finer sandpaper (from grade 300 to 1200). Then, we measured the ring-width with a LINTAB II measuring system (Rinntech Inc., Heidelberg, Germany) with a precision level of $0.01 \mathrm{~mm}$. Then, we cross-dated the tree-ring measurements to the calendar years of their formation through pattern matching and statistical tests with the software package TSAP-Win (Rinn, 2005). Finally, we used the COFECHA program to check the quality of the cross-dating to ensure exact dating for annual ring-width series $[33,34]$.

Tree-ring width data were standardized using the ARSTAN program [35] to remove growth trends related to age and stand dynamics [36]. We applied a data-adaptive power transformation to stabilize the variance and mitigate non-normality in raw tree-ring width measurement [37]. We detrended the 
tree-ring width series using a "negative exponential curve or a simple linear regression with a negative slope" [37] and then calculated tree-ring width indices as power transformed ring-width measurements minus the values of the fitted curves for each series. This procedure effectively prevents the introduction of bias into the final series, which can occur in the traditional ratio-method standardization as a result of the division process [38]. We used autoregressive (AR) modeling on each detrended series to remove temporal autocorrelation [39]. Then, we averaged all the detrended series into a chronology by computing a bi-weight robust mean to describe the overall tree growth at each site [39]. Finally, we used the Briffa Rbar-weighted method to stabilize variance in chronology in order to reduce the potential influence of decreasing the number of sampling trees [40].

We calculated inter-series correlation (Rbar) and expressed population signal (EPS) with 20-year running windows and a 10-year overlap along the chronologies. We finally used Rbar, EPS, mean sensitivity (MS), and first-order autocorrelation (AC1) to assess the quality of the chronology [41,42].

\subsection{Climate Data}

Long-term climate meteorological observations are lacking for our sampling sites. However, our previous research suggested high correlation between data from the local weather observation systems $\left(25.22^{\circ} \mathrm{N}, 99.30^{\circ} \mathrm{E}, 2350 \mathrm{~m}\right.$, installed $1.5 \mathrm{~m}$ above ground) and data recorded at Longya Meteorological Station $\left(25.12^{\circ} \mathrm{N}, 99.18^{\circ} \mathrm{E}, 1652 \mathrm{~m}\right.$, installed $1.5 \mathrm{~m}$ above ground) in 2009 [43]. Previous research also suggests that daily climate data may be more reliable than monthly climate data for assessing the tree growth-climate relationship [44-46]. We downloaded the mean daily temperature and precipitation data from 1951 to 2018 from the National Meteorological Information Center of China [30] for our assessment. In order to test our hypotheses, we also correlated our tree-ring width data with the monthly Palmer Drought Severity Index (PDSI), which is an indicator of soil moisture availability. The PDSI was calculated based on precipitation, temperature, and soil-moisture content [47]. Data on the PDSI from 1901 to 2017 were downloaded from the Royal Netherlands Meteorological Institute (KNMI) climate explorer (http://climexp.knmi.nl) for areas close to BSY and BSA $\left(25.25^{\circ} \mathrm{N} / 99.25^{\circ} \mathrm{E}\right)$, and close to LJY $\left(26.75^{\circ} \mathrm{N} / 100.25^{\circ} \mathrm{E}\right)$.

\subsection{Statistic Analysis}

\subsubsection{Long-Term Growth}

We converted the raw tree-ring width data into Basal area increment (BAI) by assuming a circular shape of the stem and using Equation (1). Since BAI is a good proxy for aboveground biomass change [48]. It can be used to quantify forest productivity (woody production) trends over long time scales [21]. Tree productivity increases with tree age until the tree begins to decline or die. We conducted this analysis with the package "dpIR" [49] in the R programming language [50].

$$
\mathrm{BAI}_{n}=\pi\left(R_{n}^{2}-R_{n-1}^{2}\right)
$$

where $R$ is the radius of the tree and $n$ is the year of tree-ring formation.

We also carried out a conservation detrending method. First, BAI was converted to normalized BAI (NBAI) using Z-scores (a dimensionless variable making among-tree variation in growth comparable). Then, an age-related trend of NBAI series was computed (cambial age was considered at core height). We obtained BAI indices using Equation (2).

$$
\text { BAI index } i j=\text { observed } \mathrm{NBAI}_{i j}-\mathrm{NBAI}_{j}
$$

where BAI index $i j$ stands for the value calculated for the year $j$ in the tree $i$; observed $\mathrm{NBAI}_{i j}$ is the normalized BAI value of the year $j$ in the tree $i$; and $N B A I_{j}$ is the calculated age-related normalized BAI value for the year $j$. 


\subsubsection{Growth-Climate Relationship}

We gathered a number of independent and dependent variables to test the growth-climate relationship. In the low-latitude regions of Asia, the onset of cambium activity in pine trees starts around May and ends in September [44,51]. Thus, we selected the daily temperature and precipitation from October 1st in the previous year to September 30th in the current year as the independent variables. We treat the temperature or precipitation during each day as an independent variable. Given that there are 365 days for temperature and 365 days for precipitation, the total number of independent variables is around 730. The dependent variables are tree-ring width indices for pine trees. We treat the value of each tree-ring width in each year as one observation. There were 33 observations from 1984 to 2016 at BSY and BSA and 47 observations from 1970 to 2017 at LJY.

We used Partial Least Square (PLS) regression to analyze the response of tree-ring width to variations in daily temperatures and precipitation during all 365 days of the year based on data from 1983 to 2016 (1970 to 2017 at LJY). PLS (Figure 3) is a technique that reduces the number of independent variables to a smaller set of uncorrelated components using the ideas of principal component analysis and canonical correlation analysis. Then, PLS performs multiple regression on dependent variables and the components of independent variables [52,53]. This process works efficiently in situations such as ours where the number of independent variables substantially exceeds the number of observations and independent variables are highly auto-correlated.

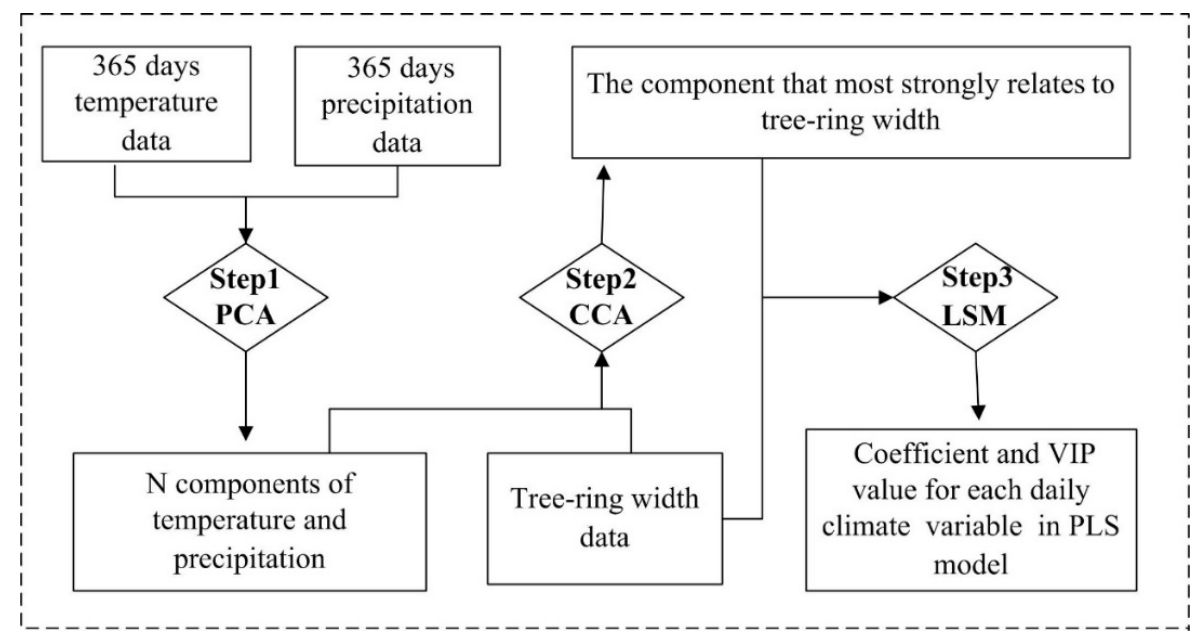

Figure 3. Framework of implementing Partial Least Square Regression (PLS) based on daily temperature and precipitation data and tree-ring widths of pine trees. $\mathrm{N}=$ total number of observations. PCA (principal component analysis) is used to remove the collinearity among daily temperature and precipitation data. CCA (canonical correlation analysis) was used to find the components that most strongly relate to tree-ring width. LSM (least squares method) was used for parameter estimation in the PLS model. VIP (variable importance in the projection) was used to judge the importance of each variable.

We used root mean squared errors (RMSE) to assess the performance of the PLS model [54]. We calculated the variable importance in the projection (VIP) statistic for each independent variable (each day). VIP is equal to the weighted sum of squares of the PLS loadings. The VIP indicates the importance of the independent variables for explaining variation in the dependent variable. A threshold of 0.8 is commonly assumed to signify importance [53], and we adopt this threshold for the present study. We also calculated standardized coefficient (beta values) for each independent variable, which indicate the strength and direction of the relationship of each independent variable with the dependent variable. PLS was conducted with the package "chillR" [54] in the R programming language [50]. 
To interpret the results of PLS regression, we mainly considered the overall impact of multiple continuous independent variables (a continuous period) on the dependent variable, rather than the effect of a single independent variable on the dependent variable. For example, in the case that all or most of the standardized coefficients of continuous daily climate observations are positive or negative, and the average VIP for those days exceeds 0.8 ; we consider this a critical climate period (CP) for tree growth.

We further calculated the Pearson correlation coefficient [55] between tree-ring width and each $\mathrm{CP}$. Then, we used the absolute values of average standardized coefficients of each $\mathrm{CP}$, together with the correlation coefficient between $\mathrm{CP}$ and tree-ring width, to determine the relative importance of each $\mathrm{CP}$ on the dependent variable. The higher the absolute value of standardized coefficients and correlation coefficients between $\mathrm{CP}$ and tree-ring width, the more important we considered this $\mathrm{CP}$ to be for tree growth.

\section{Results}

\subsection{Chronology Statistics}

All chronologies reveal high Rbar values, indicating that all chronologies are suitable for the study of the growth-climate relationship (Table 1). The growth of P. yunnanensis at LJY had the lowest rates, followed by $P$. armandii at BSA. The highest value of MS was found for P. yunnanensis in Lijiang, and then for P. armandii in Baoshan. Those results suggest that the growth of P. yunnanensis in Lijiang is more sensitive to environmental changes, followed by the growth of P. armandii in Baoshan.

\subsection{Long-Term Growth Trend}

We found that the BAI value of pine trees significantly increased until the beginning of this century and then displayed a significantly decreasing trend (Figure 4). The year with the highest BAI value for P. yunnanensis was 2002 at BSY, 2003 at LJY, and 1998 for P. armandii at BSA. Species-specifically, the change trends for P. armandii were higher than those for P. yunnanensis in Baoshan as indicated by higher standardized coefficients. Site-specifically, the change trends for P. yunnanensis were stronger at LJY than those at BSY. 

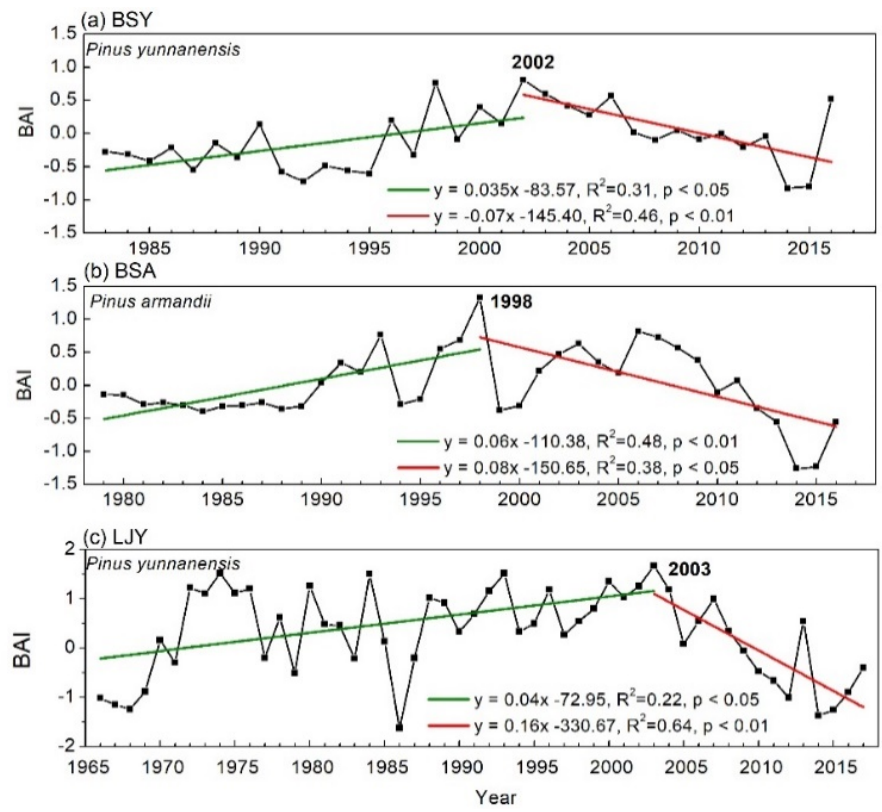

Figure 4. Change trends in the normalized basal area increments (BAI) of Pinus yunnanensis (102 cores) at BSY (a) and LJY (c) and Pinus armandii (103 cores) at BSA (b) in Baoshan and Lijiang, Yunnan, southwest China. BSY $=$ (Baoshan yunnanensis) site where P. yunnanensis samples were collected in Baoshan. BYA = (Baoshan armandii) site where P. armandii samples were collected in Baoshan. LJY $=$ (Lijang yunnanensis) site where P. yunnanensis samples were collected in Lijiang.

\subsection{Critical Climate Periods for Pine Tree Growth}

The PLS model revealed four CPs (critical climate periods) for the growth of P. yunnanensis (Figure 5a, CP1 to 4) at BSY, five CPs for the growth of P. armandii (Figure 5b CP5 to 9) at BSA, and six CPs for the growth of P. yunnanensis (Figure 5c, CP10 to 15) at LJY. RMSE values indicated a predicted error of less than $10 \%$ in the PLS models. 
(a) BSY
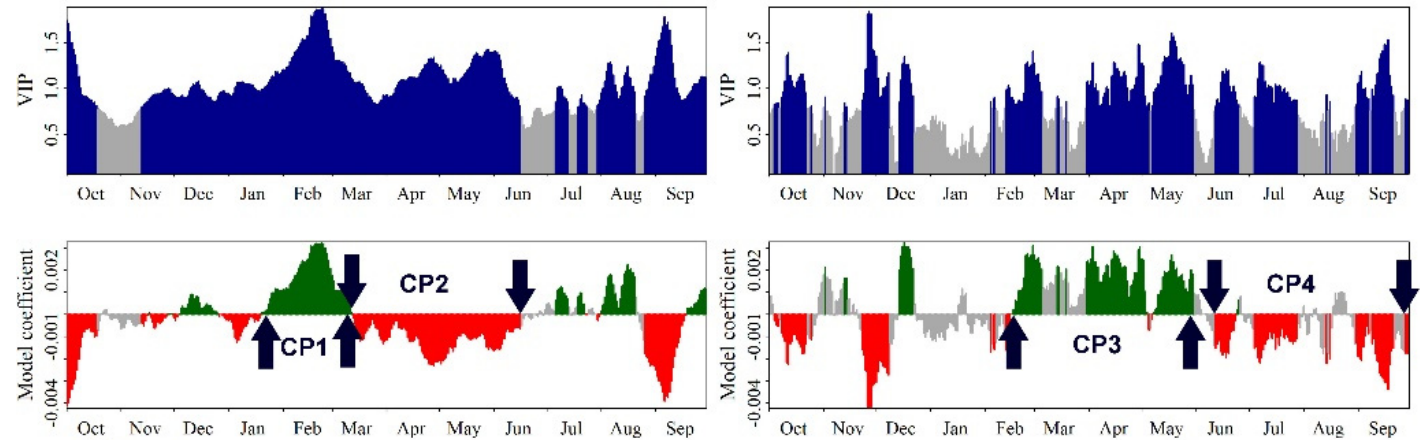

(b) BSA
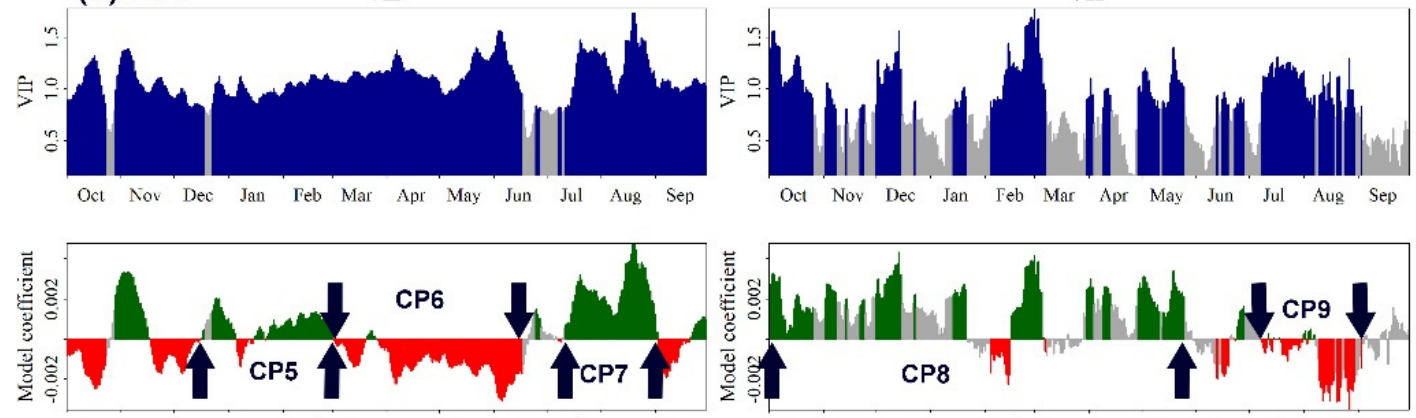

(C) LJY
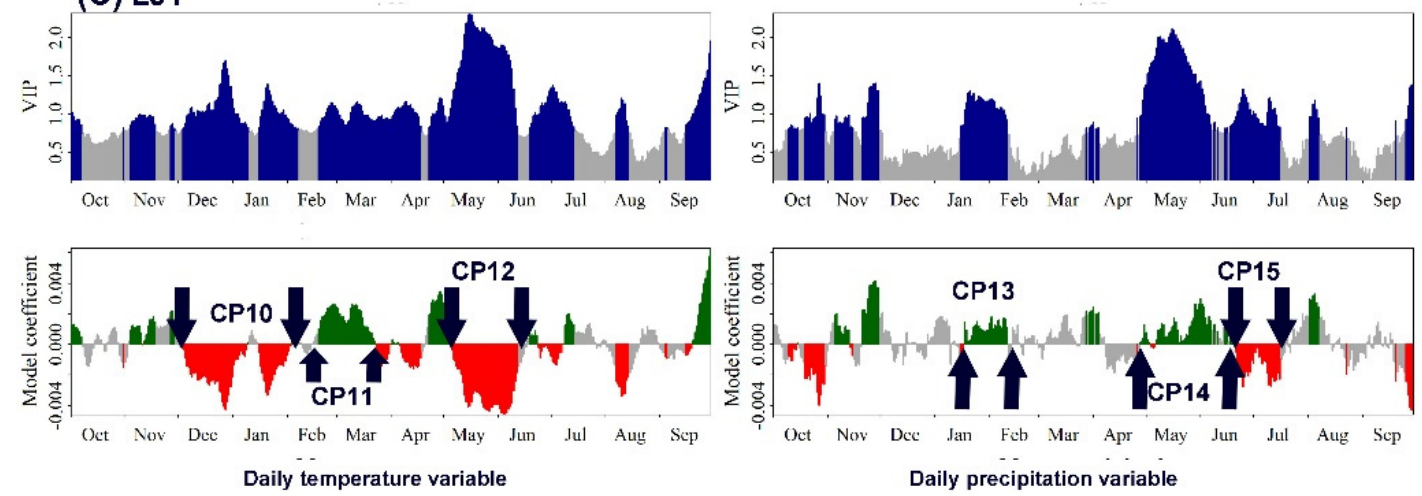

Figure 5. Results of Partial Least Squares (PLS) regression for correlating tree-ring widths of Pinus yunnanensis (a) at BSY and Pinus armandii (b) at BSA, and P. yunnanensis (c) at LJY in Yunnan from 1983 to 2016 (1967 to 2017 at LJY) with 15-day running means of daily mean temperature (left panel), daily precipitation (right panel) from the previous October to September. VIP (variable importance in the projection) was used to judge the importance of each variable. CP1 to CP15 indicate critical climate periods $(\mathrm{CP})$, with variable importance (VIP) greater than the threshold of 0.8 . BSY = (Baoshan yunnanensis) site where $P$. yunnanensis samples were collected in Baoshan. BYA = (Baoshan armandii) site where P. armandii samples were collected in Baoshan. LJY = (Lijang yunnanensis) site where $P$. yunnanensis samples were collected in Lijiang.

Based on the average standardized coefficient of each CP in the PLS models and the significance of the Pearson correlation coefficient between each CP and tree-ring widths (Table 2), we found that: (1) The precipitation from February 23 to May 30 (spring) had a positive, and the strongest, relationship with the radial growth of $P$. yunnanensis and a negative relationship with the temperature from March 13 to June 11 (spring) at BSY. The growth of $P$. armandii was positively related to precipitation from October 1 to May 25 (winter-spring) and negatively related to the temperature from March 13 to June 11 (spring) and the precipitation from July 8 to August 30 (summer) at BSA. (2) Temperature 
from May 6 to June 12 (late-spring) was negatively associated with the growth of P. yunnanensis as were temperature from December 4 to January 31 (winter) and precipitation from June 21 to July 16 (summer) at LJY.

Table 2. Critical climate period (CP) for pine growth in Yunnan, southwest China indicated by standardized coefficients from Partial Least Square (PLS) regression models and as well as Pearson the correlation coefficients between CP and tree-ring widths for pine trees in Baoshan and Lijiang, Yunnan.

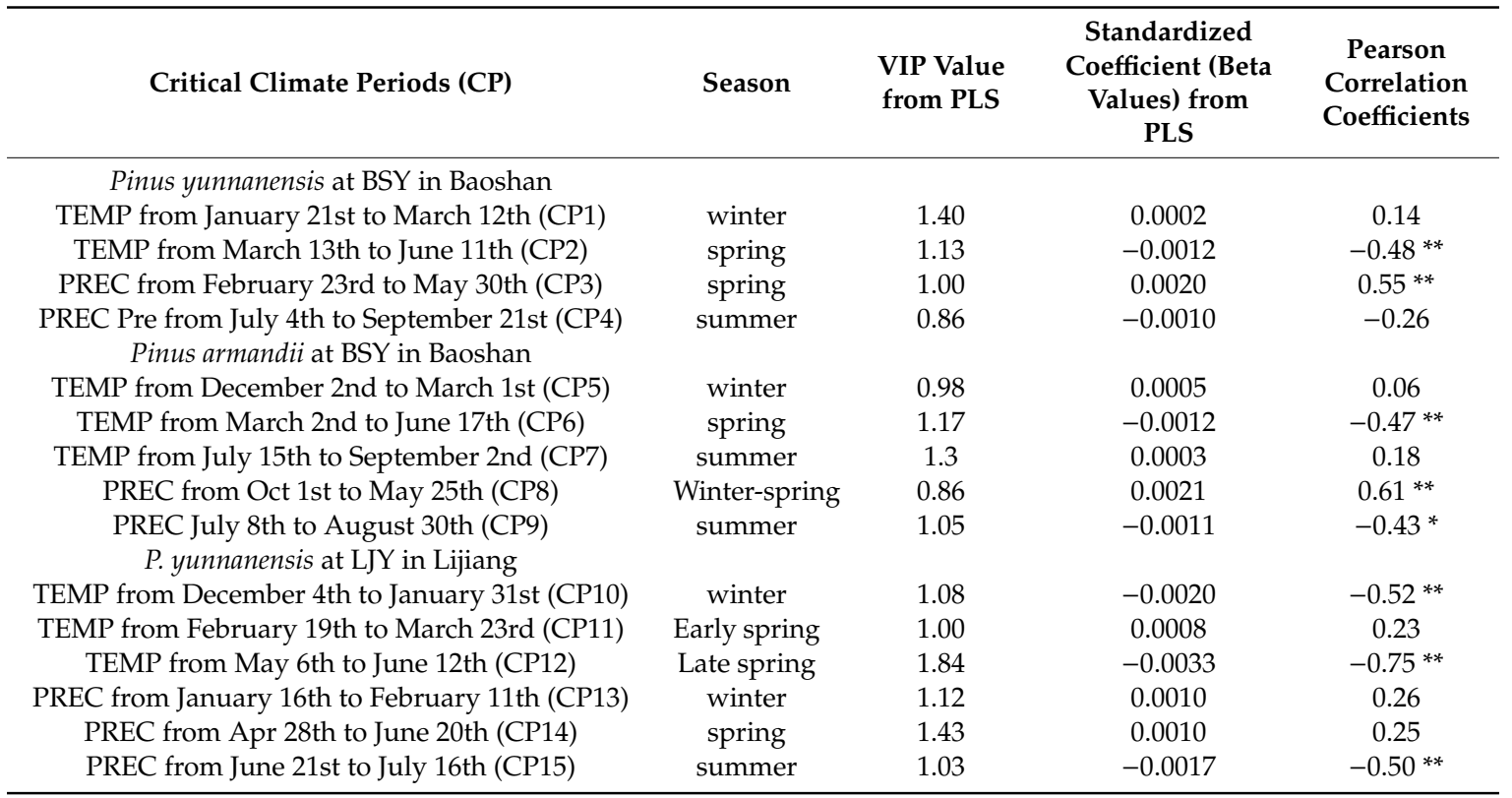

TEMP: temperature; PREC: precipitation; PLS: Partial Least Square (PLS) regression; CP1-15: critical climate period $(C P)$ that is shown in Figure 5; * significant at 0.05 level; ** significant at 0.01 level. Sites in Yunnan, southwest China: BSY $=($ Baoshan yunnanensis $)$ site where Pinus yunnanensis samples were collected in Baoshan. BYA $=($ Baoshan armandii) site where Pinus armandii samples were collected in Baoshan. LJY = (Lijang yunnanensis) site where P. yunnanensis samples were collected in Lijiang.

Overall, pine tree growth in Baoshan and Lijiang was most limited by high temperatures and low precipitation in spring. We also found that the radial growth of both species is significantly and positively correlated with PDSI from December to June, with the highest correlation coefficient in spring (Figure 6a). This suggests that the spring soil moisture availability is the main limiting factor for pine tree growth in this region.

Regarding species, we found higher correlation coefficients between tree-ring widths and spring PDSI and precipitation for P. armandii than that for P. yunnanensis in Baoshan. Results also suggest that the growth of $P$. armandii was also limited by high precipitation in summer. Regarding sites, the growth of $P$. yunnanensis was mainly limited both by high temperature and low precipitation in the spring season at BSY, while its growth was most strongly limited by high temperatures in late spring, low temperatures in winter, and high precipitation in summer at LJY. We also found that the long-term growth trends were consistent with spring PDSI (Figure 6b,c). Since the year 2000, the PDSI has decreased, and the growth of both species has shown a decreasing trend. This trend is relatively prominent for P. armandii at BSA and for P. yunnanensis at LJY. 

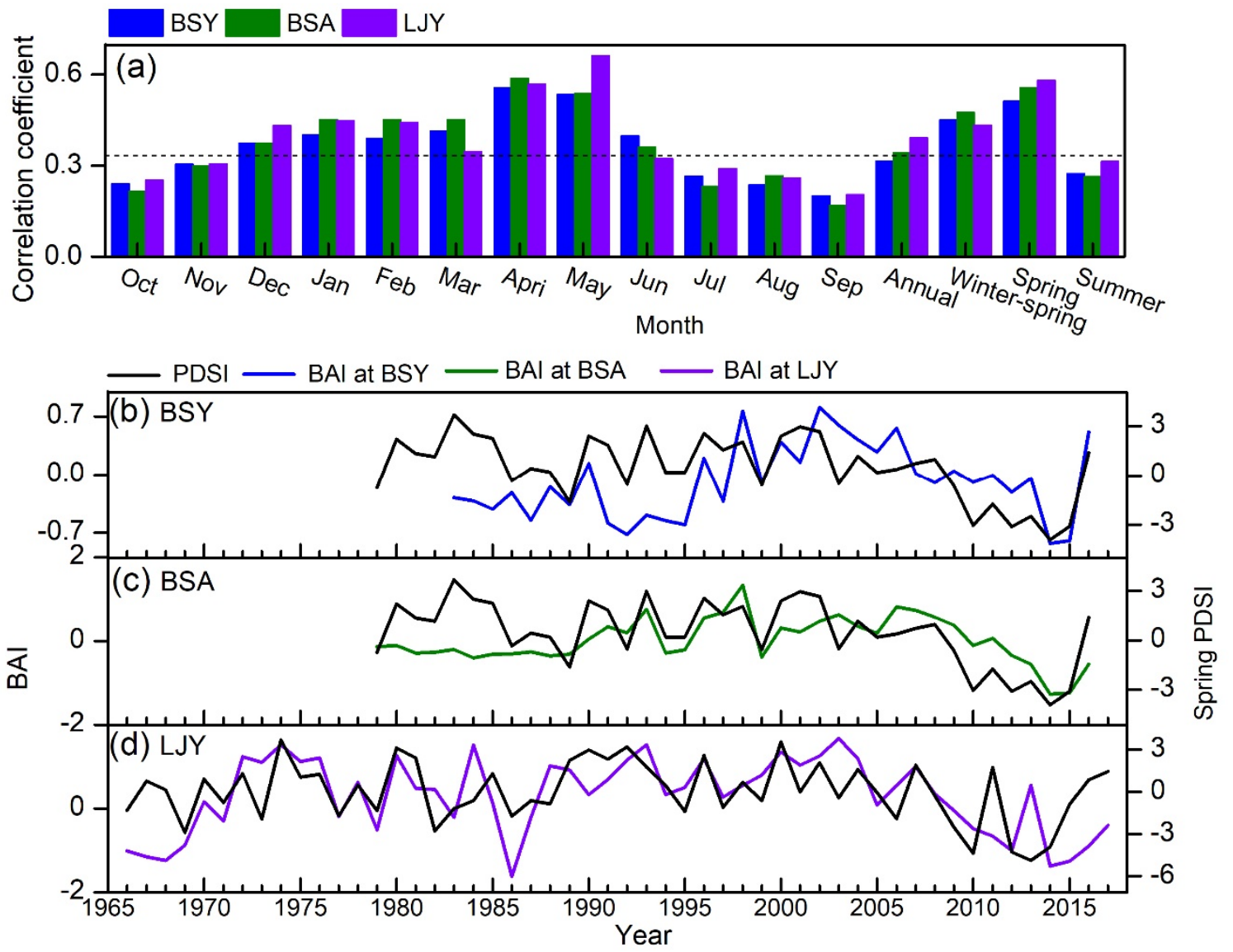

Figure 6. The relationship between tree-ring widths and Palmer Drought Severity Index (PDSI) and correlation coefficients between tree-ring widths of Pinus yunnanensis and Pinus armandii and PDSI, horizontal dashed line denotes the 99\% confidence intervals (a); Long-term variability of spring PDSI and normalized basal area increment (BAI) of P. yunnanensis ( $\mathbf{b}$ and $\mathbf{d}$ ) and P. armandii (c) in Baoshan and Lijiang, Yunnan, southwest China. BSY = (Baoshan yunnanensis) site where P. yunnanensis samples were collected in Baoshan. BYA = (Baoshan armandii) site where P. armandii samples were collected in Baoshan. LJY = (Lijang yunnanensis) site where P. yunnanensis samples were collected in Lijiang.

\section{Discussion}

\subsection{Assessing Long-Term Growth Trends of Pine Trees}

Yunnan's forest area makes up the largest component of the "Southwest Forest Region" in China [4,9] and 52\% of Yunnan's forested land and 32\% of total timber volume [16] is pine. These pine trees are important for China's carbon balance because they absorb an estimated 4.65 billion tons of carbon [56]. We found that the productivity of the two dominant pine trees in Baoshan and Lijiang in Yunnan, southwest China, began to decline at the beginning of this century (Figure 4 and Figures S5 and S6). This result supports our first hypothesis that the productivity of pine trees has begun to decline in recent decades. Yang et al. (2018) and Shi et al. (2017) also found that the radial growth of P. yunnanensis began to decline after the 2000s in nearby Lijiang and Shangri-La in Yunnan. Pine forest die-off episodes have also been frequently reported since the early 2000s in Yunnan [16-18]. The decline in the productivity of these dominant species in pine forest in Yunnan is expected to affect southwest China's carbon budget, and it may have a negative effect on the regional and global climate.

\subsection{Spring Soil Moisture Availability is the Main Limiting Factor for Pine Tree Growth}

The productivity of forests may largely depend on their growth-climate relationship under climate change [2]. Here, we investigated the growth-climate relationship of two dominant pine 
tree species in Baoshan and Lijiang, Yunnan. We found the highest positive correlation coefficient between tree-ring widths and PDSI during the spring season (Figure 6a). Since PDSI is generally considered an indicator of soil moisture availability [47], we suggest that the radial growth of pine trees was mainly limited by spring moisture availability, which supports our hypothesis that the spring water regime is the main limiting factor for the growth of pine forests. Previous research also found that the radial growth of Tsuga dumosa (D. Don) Eichler, Picea likiangensis (Franch.) E. Pritz., Abies georgei Hand.-Mazz., and P. yunnanensis were also significantly limited by low soil moisture availability in Lijiang $[9,18,57]$. Similar growth-climate relationships were also observed in north Vietnam, north Thailand, and Himalaya regions for Cedrus deodara (Roxburgh) G. Don, Pinus gerardiana Wall. ex D.Don, Pinus kesiya Royle ex Gordon, and Pinus merkusii Jungh. \& de Vriese [51,58,59]. Spring is the pre-monsoon season in our study sites (Figure 2), the soil moisture during spring mainly comes from precipitation. Higher precipitation results in higher moisture availability and reduces drought stress on tree growth. The positive relationship between tree-ring width and precipitation during spring provided further evidence for the importance of water conditions in spring on for pine tree growth.

We also found a negative relationship between tree-ring widths and temperature during the spring season. This may be due to higher temperatures intensifying plant transpiration and decreasing the moisture availability in the soil, which may delay the onset of cambium activity and thus shorten the xylem formation duration $[51,60]$. We also found that the growth of both species was negatively affected by summer precipitation (Table 2). Similar growth-response patterns were also found for A. george at Shika Snow Mountain in northwest Yunnan [61]. The summer monsoon increases low-level cloud cover and the frequency of foggy conditions, reducing the amount of solar radiation (Figure 2b,d) and resulting in lower temperatures. Low summer temperatures can decrease the rates of cambial growth and xylem cell production [59] and lead to narrower tree-rings. This negative relationship between tree growth and summer precipitation is further supported by our finding of positive relationships between tree growth and summer temperatures (Table 2).

\subsection{Spring Soil Moisture Availability is More of a Limitation for the Growth of P. armandii than P. yunnanensis in Baoshan}

We found that the radial growth of $P$. armandii is significantly correlated to precipitation from winter to spring, while the growth of $P$. yunnanensis was only significantly correlated with spring precipitation. The correlation coefficient is higher between tree-ring width and precipitation and PDSI for $P$. armandii than that for $P$. yunnanensis (Table 2). This suggests that the growth of $P$. armandii is more sensitive to soil moisture before the growing season. This difference in climate-growth response may be due to the differences in the physiological traits of the trees. P. armandii tend to have bigger stomata, lower stomata density, thinner epidermis, thinner cuticles, and looser mesophyll tissue [62]. All these physiological differences mean that $P$. armandii is less drought-tolerant than P. yunnanensis.

\subsection{Spring Soil Moisture Availability is More of a Limitation on the Growth of P. yunnanensis in Lijiang than in Baoshan}

We found higher positive correlations between the tree-ring width of P. yunnanensis and PDSI in Lijiang than that in Baoshan. This difference in climate-growth response appears mainly to be due to the differences in site conditions. LJY is around $250 \mathrm{~km}$ northeast to BSY, and the literature suggests that precipitation gradually decreases from south to north and from east to west in Yunnan, especially in spring [63]. Spring in Lijiang is drier than in Baoshan with around 9.8\% of annual precipitation falling in spring in Lijiang and 16\% in Baoshan according to the meteorological station records. This may indicate that $P$. yunnanensis is more sensitive to spring soil moisture availability when it is growing at its northeast distribution areas than when growing at its southwest distribution areas. 


\section{Conclusions}

Future forest productivity under climate change is likely to depend more and more on the growth-climate relationship. Pine forests are the critical component of the low-latitude forests of southwest China and are the most important commercial timber forests in the region. However, little attention has been given to how these pine forests respond to climate warming. Our assessments of productivity trends and the growth-climate relationships of P. yunnanensis and P. armandii in Baoshan and Lijiang indicate that total productivity increased until the beginning of this century, with the highest increasing rate in P. armandii. The productivity of both species then started to decline with highest decreasing rate in P. yunnanensis in Lijiang in this century. Spring moisture availability appears to be the main limiting factor for pine tree growth, especially for the growth of P. yunnanensis in Lijiang and P. armandii in Baoshan. Our results suggest that the radial growth of both species at both sites may be continually depressed by regional warming and warmth-induced drought conditions. We suggest the wide-scale adoption of mixed forests to enhance the adaptive ability of pine forests in China and allow them to maintain their role as carbon sinks. Our innovative approach provides a means of evaluating the growth-climate relationship at fine temporal scales. These approaches can be employed to understand possible future climate change-related tree growth and environment relationships in other ecosystems.

Supplementary Materials: The following are available online at http://www.mdpi.com/1999-4907/11/4/446/s1, Figure S1: Temperature (left panel) and precipitation (right panel) variation at multiple temporal scales at Longya Meteorological Station (1951-2019) in Baoshan. Probability values of the linear regression model according to F-test are indicated with ${ }^{* *}$ where $p<0.001$. The slope value indicates the coefficient of the linear regression model for rates of change in temperature and precipitation across years. Figure S2: Temperature (left panel) and precipitation (right panel) variation at multiple temporal scales at Lijiang Meteorological Station (1951-2019) in Lijiang. Probability values of the linear regression model according to F-test are indicated with *** where $p<0.001$. The slope value indicates the coefficient of the linear regression model for rates of change in temperature and precipitation across years. Figure S3: Relative humidity variation at multiple temporal scales at Longya Meteorological Station (1951-2019) in Baoshan. Probability values of the linear regression model according to F-test are indicated with * where $p<0.05$ or ${ }^{* *}$ where $p<0.001$. The slope value indicates the coefficient of the linear regression model for rates of change in relative humidity across years. Figure S4: Relative humidity variation at multiple temporal scale at Lijiang Meteorological Station (1951-2019) in Lijiang. Probability values of the linear regression model according to F-test are indicated with * where $p<0.05$ or $* *$ where $p<0.001$. The slope value indicates the coefficient of the linear regression model for rates of change in relative humidity across years. Figure S5: Ring-width chronologies of Pinus yunnanensis (upper panel) and P. armandi (down panel) and the number of sampling trees for each species in Baoshan. Expressed population signal (EPS) calculated with 20 -year running windows and a 10-year overlap along the chronologies. EPS greater than 0.85 indicates a reliable chronology. Figure S6: Ring-width chronology of Pinus yunnanensis and the number of sampling trees in Lijiang. Expressed population signal (EPS) calculated with 20-year running windows and a 10-year overlap along the chronologies. EPS greater than 0.85 indicates a reliable chronology.

Author Contributions: Conceptualization, X.Y. and Y.B.; Methodology, Y.B.; Software, Y.B.; Validation, Y.B. Formal Analysis, Y.B.; Investigation, Y.F.B, J.L., and J.Y.; Resources, Y.B.; Data Curation, Y.B. and C.W.; Writing-Original Draft Preparation, Y.B. and C.W.; Writing-Review \& Editing, Y.B. and C.W.; Visualization, Y.B. and C.W.; Supervision, X.Y.; Project Administration, Y.B. and X.Y.; Funding Acquisition, Y.B. and X.Y. All authors have read and agreed to the published version of the manuscript.

Funding: This research was funded by the National Natural Science Foundation of China (Grant No. 31800410), by the Chinese Academy of Sciences (CAS) "Light of West China" Program, and by the Southeast Asia Biodiversity Research Institute, Chinese Academy of Sciences (Grant No. Y4ZK111B01).

Acknowledgments: We thank Fan Zenxin from the Xishuangbanna Tropical Botanical Garden, CAS, for providing a platform for tree-ring measurement. We also thank Eike Luedeling from the University of Bonn for providing and maintaining the chillR library and for his assistance with the code for running the PLS models.

Conflicts of Interest: The authors declare no conflict of interest.

\section{References}

1. Ashton, M.S.; Tyrrell, M.L.; Spalding, D.; Gentry, B. Managing Forest Carbon in a Changing Climate; Springer: New York, NY, USA, 2012. 
2. Cap, J.; Liu, H.Y.; Zhao, B.; Li, Z.S.; Drew, D.M.; Zhao, X.H. Species-specific and elevation-differentiated responses of tree growth to rapid warming in a mixed forest lead to a continuous growth enhancement in semi-humid Northeast Asia. For. Ecol. Manag. 2019, 448, 76-84. [CrossRef]

3. Piao, S.L.; Fang, J.Y.; Ciais, P.; Peylin, P.; Huang, Y.; Sitch, S.; Wang, T. The carbon balance of terrestrial ecosystems in China. Nature 2009, 458, 1009-1013. [CrossRef] [PubMed]

4. Dai, E.F.; Wu, Z.; Ge, Q.S.; Xi, W.M.; Wang, X.F. Predicting the responses of forest distribution and aboveground biomass to climate change under RCP scenarios in southern China. Glob. Chang. Biol. 2016, 22, 3642-3661. [CrossRef]

5. Salzer, M.W.; Hughes, M.K.; Bunn, A.G.; Kipfmueller, K.F. Recent unprecedented tree-ring growth in bristlecone pine at the highest elevations and possible causes. Proc. Natl. Acad. Sci. USA 2009, 106, 20348-20353. [CrossRef] [PubMed]

6. Allen, C.D.; Breshears, D.D.; McDowell, N.G. On underestimation of global vulnerability to tree mortality and forest die-off from hotter drought in the Anthropocene. Ecosphere 2015, 6, 55. [CrossRef]

7. Babst, F.; Poulter, B.; Bodesheim, P.; Mahecha, M.D.; Frank, D.C. Improved tree-ring archives will support earth-system sciencex. Nat. Ecol. Evol. 2017, 1. [CrossRef]

8. Bi, Y.F.; Xu, J.C.; Yang, J.C.; Li, Z.S.; Gebrekirstos, A.; Liang, E.Y.; Zhang, S.B.; Yang, Y.; Yang, Y.P.; Yang, X.F. Ring-widths of the above tree-line shrub Rhododendron reveal the change of minimum winter temperature over the past 211 years in Southwestern China. Clim. Dyn. 2017, 48, 3919-3933. [CrossRef]

9. Bi, Y.F.; Xu, J.C.; Gebrekirstos, A.; Guo, L.; Zhao, M.X.; Liang, E.Y.; Yang, X.F. Assessing drought variability since 1650 AD from tree-rings on the Jade Dragon Snow Mountain, southwest China. Int. J. Climatol. 2015, 35, 4057-4065. [CrossRef]

10. Zhang, Y.; Yin, D.C.; Sun, M.; Wang, H.; Tian, K.; Xiao, D.R.; Zhang, W.G. Variations of Climate-Growth Response of Major Conifers at Upper Distributional Limits in Shika Snow Mountain, Northwestern Yunnan Plateau, China. Forests 2017, 8, 377. [CrossRef]

11. Fan, Z.X.; Braeuning, A.; Cao, K.F.; Zhu, S.D. Growth-climate responses of high-elevation conifers in the central Hengduan Mountains, southwestern China. For. Ecol. Manag. 2009, 258, 306-313. [CrossRef]

12. Li, Q.; Zhu, J.H.; Fan, L.H.; Feng, Y.; Xiao, W.F. Prediction of Forest Carbon Storage and Timber Yield Potential in Southwestern China. Ecol. Environ. Sci. 2018, 27, 416-423.

13. Wu, J.; Zhang, P.W.; Zha, J.L.; Zhao, D.M.; Lu, W.X. Evaluating the long-term changes in temperature over the low-latitude plateau in China using a statistical downscaling method. Clim. Dyn. 2019, 52, 4269-4292. [CrossRef]

14. IPCC. Intergovernmental Panel on Climate Change, Fifth Assessment Report, Working Group II: Impacts, Adaptation, and Vulnerability; Cambridge University Press: Cambridge, UK, 2014.

15. Cao, L.J.; Zhao, P.; Yan, Z.W.; Jones, P.; Zhu, Y.N.; Yu, Y.; Tang, G.L. Instrumental temperature series in eastern and central China back to the nineteenth century. J. Geophys. Res.-Atmos. 2013, 118, 8197-8207. [CrossRef]

16. Wang, L.; Zhang, J.F.; Ma, J.Z.; Wei, W.; Hu, Q. Research Progress on Pinus yunnanensis with Degradation Status and Ecosystem Functions of the Forest Stands. J. West China For. Sci. 2018, 47, 121-130. [CrossRef]

17. Yang, B.A. Investigation on Causes of Death of Yunnan Pine in Yongren County. J. Green Sci. Technol. 2016, 27-28. [CrossRef]

18. Yang, R.Q.; Fan, Z.X.; Li, Z.S.; Wen, Q.Z. Radial growth of Pinus yunnanensis at different elevations and their responses to climatic factors in the Yulong Snow Mountain, Northwest Yunnan, China. Acta Ecol. Sin. 2018, 38, 8983-8991. [CrossRef]

19. Wu, X.D.; Lin, Z.Y. A preliminary study of the modern climate change in Hengduan Mountains. Geogr. Res. 1987, 6, 48-56.

20. He, M.H.; Yang, B.; Brauning, A.; Rossi, S.; Ljungqvist, F.C.; Shishov, V.; Griessinger, J.; Wang, J.L.; Liu, J.J.; Qin, C. Recent advances in dendroclimatology in China. Earth Sci. Rev. 2009, 194, 521-535. [CrossRef]

21. Liu, B.; Wang, Y.; Zhu, H.; Liang, E.; Camarero, J.J. Topography and age mediate the growth responses of Smith fir to climate warming in the southeastern Tibetan Plateau. Int. J. Biometeorol. 2016, 60, 1577-1587. [CrossRef]

22. Yin, D.C.; Xu, D.R.; Tian, K.; Xiao, D.R.; Zhang, W.G.; Sun, D.C.; Sun, H.; Zhang, Y. Radial Growth Response of Abies georgei to Climate at the Upper Timberlines in Central Hengduan Mountains, Southwestern China. Forests 2018, 9, 606. [CrossRef] 
23. Li, Y.H. Study on diameter distribution of Pinus yunnanensis forest in plateau SW-Sichuan Province. J. Northwest For. Univ. 2018, 3, 219-225.

24. Fu, P.L.; Griessinger, J.; Gebrekirstos, A.; Fan, Z.X.; Brauning, A. Earlywood and Latewood Stable Carbon and Oxygen Isotope Variations in Two Pine Species in Southwestern China during the Recent Decades. Front. Plant Sci. 2017, 7, 12. [CrossRef] [PubMed]

25. Fu, L.; Li, N.; Elias, T.S.; Mill, R.R. Flora of China (Vol.7 PINACEAE); Science Press: Beijing, China, 1978.

26. Chen, F.L.; Chen, H.M.; Yang, Y.Y. Annual and seasonal changes in means and extreme events of precipitation and their connection to elevation over Yunnan Province, China. Quat. Int. 2015, 374, 46-61. [CrossRef]

27. Tang, C.Q.; He, L.-Y.; Su, W.-H.; Zhang, G.-F.; Wang, H.-C.; Peng, M.-C.; Wu, Z.-L.; Wang, C.-Y. Regeneration, recovery and succession of a Pinus yunnanensis community five years after a mega-fire in central Yunnan, China. For. Ecol. Manag. 2013, 294, 188-196. [CrossRef]

28. Bohner, J. General climatic controls and topoclimatic variations in Central and High Asia. Boreas 2006, 35, 279-295. [CrossRef]

29. Wen, K.G. China Meteorological Disaster Dictionary (Yunnan Volume); China Meteorological Press: Beijing, China, 2006.

30. National Meteorological Information Center. Available online: http://data.cma.cn/data/cdcindex/cid/ 6d1b5efbdcbf9a58.html (accessed on 27 November 2019).

31. Deng, X.Q.; Huang, B.B.; Wen, Q.Z.; Hua, C.L.; Tao, J. A research on the distribution of Pinus yunnanensis forest in Yunnan Province. J. Yunnan Univ. 2013, 35, 843-848. [CrossRef]

32. Wu, X.D. Dendrochronology and Climate Change; China Meteorological Press: Beijing, China, 1990; p. 368.

33. Tree-Ring Lab. of Columbia University. Cofecha: Dating and Measurement Quality Control; Tree-Ring Lab. of Columbia University: Manhattan, NY, USA, 2013.

34. Holmes, R.L. Computer-assisted quality control in tree-ring dating and measurement. Tree-Ring Bull. 1983, 43, 68-78. [CrossRef]

35. Tree-Ring Lab. of Columbia University. ARSTAN: Chronology Development, Plotting and Analysis; Tree-Ring Lab. of Columbia University: Manhattan, NY, USA, 2013.

36. Fritts, H.C. Tree Rings and Climate; Elsevier: New York, NY, USA, 1976.

37. Cook, E.R.; Peter, K. Calculating unbaised tree-ring indices for the study of climatic and environmantal change. Holocene 1997, 7, 361-370. [CrossRef]

38. Liang, E.; Leuschner, C.; Dulamsuren, C.; Wagner, B.; Hauck, M. Global warming-related tree growth decline and mortality on the north-eastern Tibetan plateau. Clim. Chang. 2016, 134, 163-176. [CrossRef]

39. Cook, E.R.; Briffa, K.R. A comparision of some tree-ring standardization methods. In Method of Dendrochronology: Application in Environmental Science; Cook, E.R., Kairiukstis, L.A., Eds.; Kluwer Acadenic Press: Dordrecht, The Netherlands, 1990.

40. Osborn, T.J.; Briffa, K.R.; Jones, P.D. Ajusting variance for sample-size in tree ring chronologies and other regional mean times series. Dendrochronologia 1997, 15, 89-99.

41. Esper, J.; Gärtner, H. Interpretation of Tree-Ring Chronologies (Interpretation von Jahrringchronologien). Erdkunde 2001, 3, 277-288. [CrossRef]

42. Wigley, T.M.L.; Briffa, K.R.; Jones, P.D. On the average value of correlated time series, with application in dendroclimatology and hydrometeorology. J. Clim. Appl. Meteorol. 1984, 23, 201-213. [CrossRef]

43. Yang, X.F.; Luedeling, E.; Chen, G.L.; Hyde, K.D.; Yang, Y.J.; Zhou, D.Q.; Xu, J.C.; Yang, Y.P. Climate change effects fruiting of the prize matsutake mushroom in China. Fungal Divers 2012, 56, 189-198. [CrossRef]

44. Sun, C.F.; Liu, Y. Climate Response of Tree Radial Growth at Different Timescales in the Qinling Mountains. PLoS ONE 2016, 11. [CrossRef] [PubMed]

45. Vaganov, E.A.; Hughes, M.K.; Kirdyanov, A.V.; Schweingruber, F.H.; Silkin, P.P. Influence of snowfall and melt timing on tree growth in subarctic Eurasia. Nature 1999, 400, 149-151. [CrossRef]

46. Feng, X.H.; Chen, R.M.; Xiao, W.F.; Wang, R.L.; Wang, X.R.; Liu, Z.B. The critical temperature to Huashan Pine (Pinus armandi) radial growth based on the daily mean temperature (In Chinese with English abstract). Acta Ecol. Sin. 2012, 32, 1450-1457. [CrossRef]

47. Mika, J.; Horvath, S.; Makra, L.; Dunkel, Z. The Palmer Drought Severity Index (PDSI) as an indicator of soil moisture. Phys. Chem. Earth 2005, 30, 223-230. [CrossRef] 
48. Babst, F.; Bouriaud, O.; Alexander, R.; Trouet, V.; Frank, D. Toward consistent measurements of carbon accumulation: A multi-site assessment of biomass and basal area increment across Europe. Dendrochronologia 2014, 32, 153-161. [CrossRef]

49. Andrew, G.B. A dendrochronology program library in R (dplR). Dendrochronologia 2008, 26, $115-124$. [CrossRef]

50. R-Core-Team. R: A Language and Environment for Statistical Computing; Foundation for Statistical Computing: Vienna, Austria, 2019.

51. Pumijumnong, N.; Wanyaphet, T. Seasonal cambial activity and tree-ring formation of Pinus merkusii and Pinus kesiya in Northern Thailand in dependence on climate. For. Ecol. Manag. 2006, 226, 279-289. [CrossRef]

52. Luedeling, E.; Zhang, M.; McGranahan, G.; Leslie, C. Validation of winter chill models using historic records of walnut phenology. Agric. For. Meteorol. 2009, 149, 1854-1864. [CrossRef]

53. Guo, L.; Cheng, J.M.; Luedeling, E.; Koerner, S.E.; He, J.S.; Xu, J.C.; Gang, C.C.; Li, W.; Luo, R.M.; Peng, C.H. Critical climate periods for grassland productivity on China's Loess Plateau. Agric. For. Meteorol. 2017, 233, 101-109. [CrossRef]

54. Luedeling, E.; Kunz, A.; Blanke, M.M. Identification of chilling and heat requirements of cherry trees-a statistical approach. Int. J. Biometeorol. 2013, 57, 679-689. [CrossRef] [PubMed]

55. Tang, Y.C. Statistical Analysis With R; High Education Press: Beijing, China, 2008.

56. Lu, H.C. Preliminary estimation of forest carbon reserves of Pinus yunnanensis. For. Invetory Plan. 2010, 35, 91-93. [CrossRef]

57. Guo, G.A.; Li, Z.S.; Zhang, Q.B.; Ma, K.P.; Mu, C.L. Dendroclimatological studies of Picea likiangensis and Tsuga dumosa in Lijiang, China. IAWA 2009, 30, 435-441. [CrossRef]

58. Masaki, S.; Brendan, M.B.; Tatsuo, S. Tree-ring based hydroclimate reconstruction over northern Vietnam fromFokienia hodginsii: Eighteenth century mega-drought and tropical Pacific influence. Clim. Dyn. 2009, 33, 331-340. [CrossRef]

59. Singh, J.; Yadav, R.R.; Wilmking, M. A 694-year tree-ring based rainfall reconstruction from Himachal Pradesh, India. Clim. Dyn. 2009, 33, 1149-1158. [CrossRef]

60. Rossi, S.; Girard, M.-J.; Morin, H. Lengthening of the duration of xylogenesis engenders disproportionate increases in xylem production. Glob. Chang. Biol. 2014, 20, 2261-2271. [CrossRef]

61. Panthi, S.; Brauning, A.; Zhou, Z.k.; Fan, Z.X. Growth response of Abies georgei to climate increasde with elevation in the central Hengduan Mountains, southwest China. Dendrochronolagia 2018, 47, 1-9. [CrossRef]

62. Wang, J.; Luo, L.C.; Lei, S.Q.; Zhang, Z.Y. A study on the eco-anatomical of extremely endangered pine of China: Pinus squamata. J. Jiangxi Agric. Univ. 2008, 30, 672-674. [CrossRef]

63. Tao, Y.; He, Q. The temporal and spatial distribution of precipitation over Yunnan Province and its response to global warming. J. Yunnan Univ. 2008, 30, 587-595. 